\title{
ANOTACIONES AL TEMA DEL CRUCIFICADO EN PEDRO DE MENA
}

\author{
POR \\ JUAN JESÚS LÓPEZ-GUADALUPE \\ Universidad de Granada
}

\begin{abstract}
We know few natural size «Crucificados» of Pedro de Mena. Or that, es very important the study of the little size «Crucificados» worked for him. Through of those «Crucificados» and the tradition of granadine's sculpture school, it cam be demostrated the existence of the natural size «Crucificados» in Pedro de Mena.
\end{abstract}

Indiscutiblemente, el del Crucificado es el tema central del arte cristiano. La cruz desnuda, símbolo de esta religión, al poco del nacimiento de la misma, se va completando con el cuerpo del mártir en una representación capital para la devoción y arte cristianos. Comienza entonces un largo camino de progresión en naturalismo y humanización que encuentra su más acabada expresión, para el caso español, en los Crucificados barrocos.

El desarrollo de los temas del «dolor» durante la Edad Moderna y las particulares notas de realismo y humanidad de la escultura barroca encuentran en el tema del Crucificado un medio idóneo para su libre desenvolvimiento. El ejercicio anatómico naturalista, la pormenorización de los tormentos de la Pasión, la explicitación de la humanidad sufriente de Cristo, su racionalización en corrientes místicas o ascéticas conforman los materiales de trabajo para los artistas que cultivan el Crucifijo de devoción barroco, introduciendo su sello con matices propios.

Por esta especial significación del tema, ha resultado siempre extraña la reducida presencia del Crucificado en la producción de un escultor de tan alta cualificación artística y tan profunda religiosidad como Pedro de Mena (1628-1688). El tema ofrecía inmejorables perspectivas para el escultor granadino: su habilidad técnica queda demostrada sobradamente, incluso en el modelado del desnudo y, por otro lado, su profunda religiosidad, tan bien plasmada en temas ascético-místicos como los santos franciscanos, debía sentirse atraída por tan capital iconografía.

Sin embargo, pocas noticias de Crucificados hechos por Mena poseemos y menos imágenes aún nos han llegado, pues la única claramente identificada de tamaño natural ardió en 1931. Ello, sin duda, constituye, junto a la fama del propio artista - abundantes encargos en la Corte y probable nombramiento como escultor de la Catedral de Toledo- una de las razones de la multiplicación de las atribuciones que la bibliografía sobre este autor nos ha ido ofreciendo 
durante largo tiempo. Prácticamente todas han sido desechadas y para colmo, muchas de las obras atribuidas en otros tiempos tampoco se conservan ${ }^{1}$.

\section{Consideraciones previas}

A esto se añade la consideración de los precedentes de este tema en la escuela granadina ${ }^{2}$. Es a finales del siglo XVI cuando el gran creador de tipos iconográficos para la escultura andaluza, el alcalaíno Pablo de Rojas, comienza una espléndida serie de Crucificados en los que apunta inequívocamente lo que Gallego Burín calificó de «instinto plástico» en la escuela granadina ${ }^{3}$. En efecto, el notable modelado de Rojas encauza en sus creaciones un naturalismo y un vigor plástico, que tendrá consecuencias en Martínez Montañés, para lograr una belleza en los desnudos de Cristo que no se alcanzaba en Granada desde Jacobo Florentino.

Definida, pues, la ecuación de realismo y emoción espiritual del Crucificado de devoción granadino, encontramos una espléndida consecuencia en el Crucificado atribuido a los hermanos García en la sacristía de la Catedral granadina, con un estrecho contacto con lo montañesino, y, sobre todo, en la serie de Crucificados de Alonso de Mena, que su hijo Pedro debió ver construir desde su infancia en el taller paterno. Son Cristos de alto componente patético que se recrean en los detalles realistas de su agonía.

Éste debió ser el modelo que directamente conociera Pedro de Mena y al que estaría abocado con su mayor talento si no irrumpiera en su tierra natal la personalidad artística de Alonso Cano. En el racionero se da igual escasez de Crucificados de escultura y, en general, de temas de Pasión, aunque los frecuente en pintura. Con él comienza una atenuación de la cruencia dolorida en estos temas que lleva a una concepción y plasmación de gran serenidad, equilibrio y belleza formal. Este nuevo rumbo queda nítidamente definido y quintaesenciado en la sucesión de los Cristos de Lecaroz, de Alonso Cano, de Santo Domingo de Málaga — perdido, como va dicho- , de Pedro de Mena y de San José de Granada, de José de Mora, serie de gran calidad artística y de honda emoción religiosa, esto fundamentalmente en los discípulos del racionero granadino.

Por ello, es de gran interés en el estudio de los Crucificados de Pedro de Mena el análisis de los modelos heredados, sopesando su importancia, cuestión en la que, como comprobaremos, el ponderado es naturalmente Alonso Cano. Otra cuestión importante es el hecho de que, ante la ausencia de Crucificados de tamaño natural, sí existan otros de pequeño formato en manos de santos y santas; lo interesante aquí es considerar el empeño que Mena pone en estas realizaciones de pequeño formato, tanto en lo que al modelo concierne (ayudándonos a puntualizar su tipo de Crucificado, a falta de imágenes de mayor formato), como en el esfuerzo técnico y conceptualizador de su ejecución. Por eso, ordenaremos a continuación lo conocido referente a este tema por orden cronológico, partiendo del tamaño natural y abordando posteriormente el pequeño formato.

\footnotetext{
1 Una revisión historiográfica de las diferentes atribuciones de Crucificados a Pedro de Mena nos ofrece Romero Torres, José Luis. «Pedro de Mena: un nuevo Crucificado». Jábega. Revista de la Diputación Provincial de Málaga, n. 35 (1981), pp. 13-20.

2 La secuencia completa del Crucificado granadino del Renacimiento y del Barroco en escultura la hemos trazado en López Muñoz, Juan Jesús et alii. Granada y el Cristo de San Agustín. Notas de historia, arte y religiosidad para la Semana Santa de Granada. Granada, 1994, pp. 179-205.

${ }^{3}$ Gallego Burín, Antonio. «Pablo de Rojas, el maestro de Martínez Montañés». Boletín de la Academia de Bellas Artes Santa Isabel de Hungría, n. 4 (1939), p. 14.
} 


\section{Sobre los Crucificados de tamaño natural en Pedro de Mena}

De Crucificados de tamaño natural de autoría cierta de Mena, nada ha quedado. Conocemos documentalmente varios. En una de sus testamentarías se menciona un Crucifijo acabado para el confesor de su Majestad, pero probablemente era un Crucifijo de alcoba, de pequeño formato. Por otro lado, da cuenta Palomino de la realización por Mena de un Crucificado para el Príncipe Doria, llamado Cristo de la Agonía, sobre estudio del natural, aunque tan sólo del tamaño de una tercia ${ }^{4}$. Debió ser obra de alto empeño para el artista que, al parecer, obsequió con ella al noble personaje y fue gratificado abundantemente por ello. El propio artista quedó sumamente satisfecho de su obra y ésta fue muy apreciada a su llegada a Génova. Debemos recordar las cordiales relaciones que la casa Doria sostuvo con la monarquía hispana durante los siglos XVI y XVII, acudiendo incluso en su ayuda contra las pretensiones anexionistas francesas ${ }^{5}$, amén de las relaciones que durante el XVI sostuvieron los talleres escultóricos genoveses con España.

El único Crucificado de tamaño natural bien conocido fue el Cristo de la Buena Muerte de la iglesia malagueña de Santo Domingo ${ }^{6}$ (fig. 1), en el incendio de la cual pereció en 1931 en unión de otros tesoros artísticos. Fue un encargo del dominico Fray Alonso de Santo Tomás, que fue obispo de Málaga, siendo su primer destino la Sala de Profundis del aquel cenobio, según atestigua Palomino. Más tarde pasó a la iglesia, en donde permaneció en lo alto del retablo mayor casi ignorado. Hacia 1883 se produce su «redescubrimiento», al ser bajado para procesionar por la cofradía del Cristo de la Buena Muerte. Según una crónica de la época, se encontraba ennegrecido y le faltaban dos dedos de una mano y uno de la otra, por lo que fue sometido a una restauración por parte del escultor Gutiérrez de León ${ }^{7}$. Renovado su culto, pereció en el mencionado incendio.

En esta imagen presentaba Mena un Cristo muy equilibrado en su composición a través de sus armoniosos perfiles cerrados, tan sólo quebrados en el paño de pureza, y de la gravedad con que cuelga de la cruz el cuerpo de Cristo, desplomado. A ello contribuye lo sobrio del modelado, blando y sin exageraciones anatómicas, que traza un cuerpo de gran verticalidad, con el vientre hundido y el tórax hinchado. El breve perizoma se complica un tanto en la zona púbica y deja al descubierto el lado izquierdo de la cadera, cruzado sólo por la cuerda que lo ciñe. En este lado, un no muy amplio trozo de paño volado marca la inflexión y proporción entre tronco y extremidades, afectando a la nitidez de contornos de la bella figura.

La hermosa cabeza reposaba sobre el pecho, hundiéndose ladeada a su derecha (fig. 2). El rostro, lejos de exageraciones patéticas, mostraba un excelente trabajo en sus clásicas facciones, de acusado perfil en la nariz, como se observa en otras obras de Mena, y con la severidad que imprime el sello de la muerte en su faz, con las órbitas hundidas y las facciones rígidas, los ojos rasgados y los párpados muy planos. De cualquier forma, apreciaciones de este tipo se relativizan al no conocer directamente la obra, sino a través de antiguas reproducciones fotográficas.

\footnotetext{
${ }^{4}$ Palomino de Castro y Velasco, Antonio Acisclo. El museo pictórico y escala óptica. Madrid, 1715. Edición de Madrid, Aguilar, 1947, p. 1067. Martín González, Juan José. «Pedro de Mena visto desde Castilla». En Pedro de Mena. III Centenario de su muerte. 1688-1988. Málaga, 1989, p. 72. Como se sabe, una tercia equivale a unos veintiocho centímetros.

${ }_{5}^{5}$ Recordemos El socorro de Génova por el Marqués de Santa Cruz - hecho de armas acaecido en 1625- que Antonio de Pereda pintó para el Salón de Reinos del Palacio Real.

${ }^{6}$ Orueta y Duarte, Ricardo de. La vida y la obra de Pedro de Mena y Medrano. Madrid, Centro de Estudios Históricos, 1914, pp. 149-152 (edición facsímil en Málaga, Colegio de Arquitectos-Universidad, 1988, con prólogo de Domingo Sánchez-Mesa Martín). Blay, Miguel. «Crucifijo. Parroquia de Santo Domingo. Málaga». En Pedro de Mena, escultor. Homenaje en su tercer centenario (1628-1928). Málaga, Sociedad Económica de Amigos del País, 1928, s.p.

7 Anónimo. «Descubrimiento artístico importantísimo». Boletín de la Real Academia de Bellas Artes de San Fernando, t. III (1883), pp. 190-191.
} 

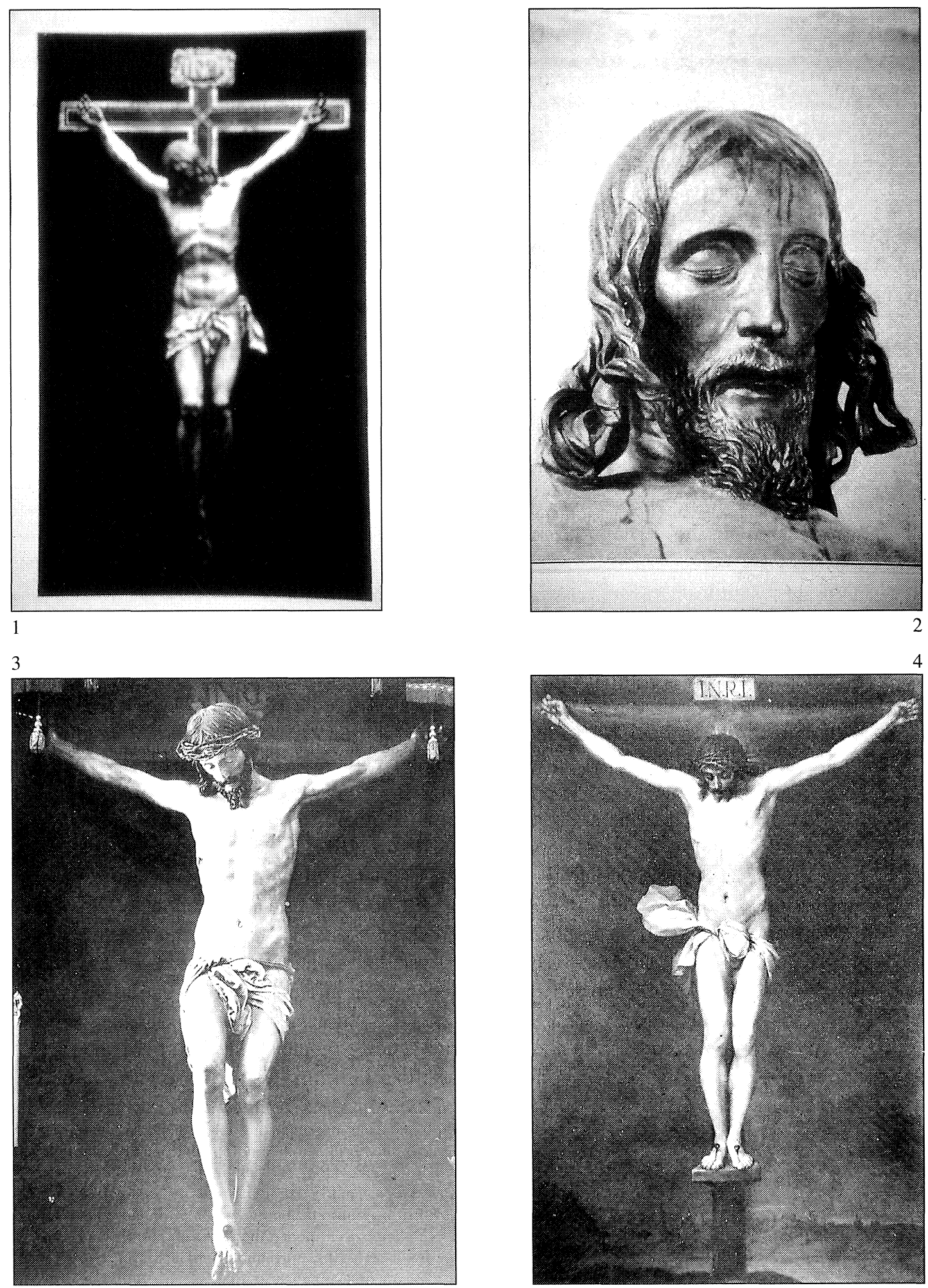

Figs. 1-2. Pedro de Mena: Cristo de la Buena Muerte. Hacia 1663-1664. Málaga, iglesia de Santo Domingo (destruido). Conjunto y detalle

Figs. 3-4. Alonso Cano: Crucificados. Lecaroz (Navarra), iglesia de los Capuchinos (anterior a 1660) y Madrid, Academia de San Fernando (hacia 1646). 
Muy interesante, sin embargo, es el problema de la proporción. El Crucificado era ostensiblemente corto de brazos, cuya longitud califica Orueta de «una mezquindad inverosímil» 8 . Extrañaría mucho tal defecto en tan avezado escultor y, con buen criterio, ya apuntaron, tanto Orueta como María Elena Gómez-Moreno, que se trataba de un efecto consciente y no de un defecto. Como en el caso del Cristo de la Clemencia de Martínez Montañés, esta desproporción es propicia para cierto tipo de perspectiva, aquella que proporciona la cercana contemplación, fundamentalmente al pie mismo de la imagen, sea en pie o arrodillado. Ello lleva a afirmar a Orueta que si, como informa Palomino, tuvo esta imagen su primer destino en la Sala de Profundis, debió estar colocada en uno de los lados largos, en donde el Cristo siempre se vería de cerca por no haber espacio para retirarse más ${ }^{9}$.

Para establecer su cronología, la indagación sobre sus posibles modelos resulta esencial y esta cuestión señala claramente hacia Alonso Cano. Especialmente relevante es la relación con el Cristo de los Capuchinos de Lecaroz (fig. 3) del racionero. Este Crucificado de tres clavos, recogido èn la Academia de San Fernando en dos ocasiones, procedente del monasterio de PP. Benedictinos de Montserrat de Madrid, fue finalmente depositado en el monasterio navarro en 1891. Dos pésimas restauraciones (en 1824 y hacia 1891) nos lo presentan hoy muy alterado en su policromía e incluso en su modelado, pero basta para advertir un concepto vertical y equilibrado de la composición que está lejos de lo conocido hasta entonces en Granada. Las relaciones del Crucificado malagueño de Mena con éste de Cano son evidentes: la actitud general de la figura, en su verticalidad y serenidad, las piernas estiradas y ligeramente unidas en las rodillas, el modo de caer de la cabeza e incluso en el ceñido del paño, aunque más volado en Mena. En ambos casos, el perizoma se sujeta por una cuerda y deja desnuda la cadera izquierda, cruzando el paño el muslo en el caso de Cano. La cronología del de Cano es discutida, si bien es anterior a 1660 .

Por si esto no bastara, debemos recordar que Cano se desenvuelve, aquí como en la mayor parte de su producción escultórica, en un concepto muy cercano a lo pictórico, como demuestran algunas de las pinturas de Crucificados que se le atribuyen, emparentado con el concepto velazqueño, heredado por ambos de Pacheco.

Precisamente, donde más cerca se encuentra Cano de Pacheco es en el Crucificado de la Academia de San Fernando (fig. 4), que Wethey fecha hacia $1646{ }^{10}$, en el que sigue el modelo iconográfico de cuatro clavos que defendía el maestro sevillano. Es el más vertical de sus Crucificados, sumido en una inmensa placidez. Pero, sin duda, el más directamente relacionado con el de Lecaroz es el lienzo que se le atribuye en la Academia de Bellas Artes de Granada (fig. 5), fechado por Wethey hacia $1652^{11}$. La disposición general de la figura, con tres clavos y la cabeza levemente girada a la derecha, y, sobre todo, la composición del perizoma así lo confirman. Cano muestra en este lienzo un Crucificado de musculoso modelado, más potente y enérgico que en el de escultura, aunque bien pudiese deberse esta carencia en el de Lecaroz a las manipulaciones sufridas. Con este efecto, el Crucificado de la Academia granadina gana en intensidad con respecto a los anteriores, lo cual se puede rastrear en el de Mena, incluyendo el ensombrecido rostro de Cristo en el lienzo de Cano que logra Mena con una inclinación de la cabeza que deja el rostro en penumbra. No deben extrañarnos este tipo de efectos pues,

\footnotetext{
${ }^{8}$ Orueta y Duarte, R. de, op. cit., p. 149.

9 Ibidem, pp. 149-150. María Elena Gómez-Moreno sentencia la cuestión: «Montañés y Mena entendían de escultura bastante más que sus críticos» (Gómez-Moreno, María Elena. «Pedro de Mena y los tipos iconográficos». En Pedro de Mena. III Centenario de su muerte. 1688-1988, p. 92).

${ }^{10}$ Wethey, Harold E. Alonso Cano. Pintor, escultor y arquitecto. Madrid, 1983, p. 63.

"Ibidem, pp. 73 y 117.
} 

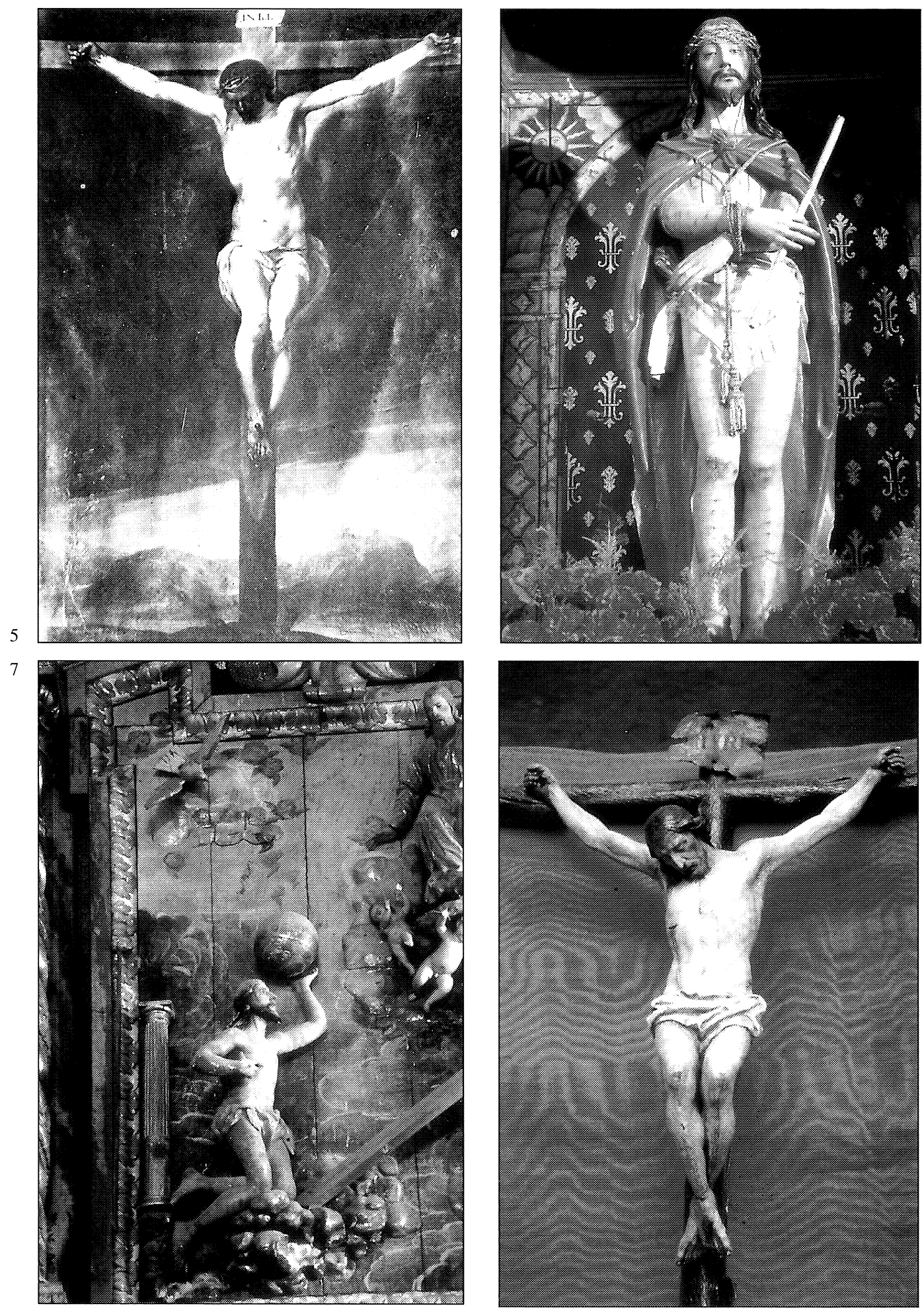

Fig. 5. Alonso Cano: Crucificado (hacia 1652), Granada, Academia de Bellas Artes.

Fig. 6-7. Taller de Pedro de Mena: Ecce-Homo (segundo tercio del s. xvII) y Cristo Salvador (h. 1667-71), Granada, iglesia de Santa María de la Alhambra.

Fig. 8. Pedro de Mena: Crucificado de la imagen de San Francisco de Asís (entre 1653 y 1661), Granada, Convento del Ángel Custodio. 
como nos recuerda Orozco, Pedro de Mena debió acostumbrarse a frecuentar modelos pictóricos en el taller de su padre ${ }^{12}$.

El modelo canesco es, pues, evidente. La única modificación introducida por Mena es la desproporción de brazos intencionada y el más acusado ángulo de éstos con relación al tronco, debido al mismo efecto. Por lo demás, éste es el influjo que aparta a nuestro escultor de las menos serenas y más dramáticas representaciones de su padre, Alonso. Inspira a su Crucificado un tono general de serenidad y equilibrio, aunque sin alcanzar plenamente los tintes de idealidad y clasicismo perseguidos por su maestro Cano. Y es que, en este sentido, Pedro de Mena resulta mucho más accesible para la devoción popular.

Todo incita, por tanto, a fechar el Cristo malagueño después de 1663, fecha probable del viaje de Mena a Madrid, en el que tendría la oportunidad de conocer directamente el Crucificado de Cano en Montserrat. De todos modos, es probable que tuviera ya Mena el recuerdo del Cristo de la Academia granadina, que abre la serie. Además, conviene anotar la presencia de Cano en Málaga en 1665-1666, al servicio del mismo mecenas que Mena, el prelado Fray Alonso de Santo Tomás, quien tomó posesión de la sede malacitana el 24 de diciembre de 1664. Según Palomino, fue precisamente fray Alonso, todavía provincial de los dominicos, el comitente del famoso Crucificado, por lo que debe fecharse entre el viaje a Madrid y la promoción a la mitra malagueña del fraile de la orden de los predicadores.

Habida cuenta que no se conserva ningún ejemplar de su mano de gran formato, el estudio de la tipología del Crucificado del maestro granadino debe apoyarse necesariamente en la huella que deja en su taller. Incluso su análisis se revaloriza aún más en el contraste con otros desnudos de Cristo que se relacionan con su estilo. En la iglesia granadina de Santa María de la Alhambra, Orozco atribuye a Mena un Ecce-Homo (fig. 6) de cuerpo entero y tamaño natural ${ }^{13}$. Los brazos cruzados ante el pecho y el manto rojo que allí se anuda nos impiden estudiar el modelado del torso, pero en el de las piernas encontramos la misma tónica de suavidad y morbidez, incluso en la policromía, en la manera de detallar heridas y moratones, si bien su modelado aparece más simplificado, salvo en sus excelentes manos. El paño se dispone de manera diferente, pero siempre muy ceñido, valorando diferentes planos con pliegues suaves, poco resaltados. No alcanza, en general, la intensidad plástica y expresiva del maestro, pero sí contribuye a delimitar caracteres concretos de su estilo en el tratamiento del desnudo de Cristo.

Otro término de comparación podría ser el Cristo Salvador del grupo de la Santísima Trinidad que corona el retablo de la propia iglesia de Santa María de la Alhambra (fig. 7). Ya se ha apuntado una posible colaboración de Pedro de Mena en el mencionado retablo ${ }^{14}$, construido entre 1667 y 1671 por Juan López de Almagro. No extraña la participación del taller de Mena en esta obra, pues sabido es que continuaba sirviendo encargos a su ciudad natal. Sin embargo, este Cristo Salvador se interpreta con más poderosa anatomía, con más eco del propio Alonso de Mena que de su hijo, si bien lo simple y sobrio del modelado sí refleja soluciones plásticas en la línea de Pedro. En poco se asemeja el paño de pureza al resto de lo conocido de Mena, salvo en su disposición triangular, por lo voluminoso y complejo de su plegado.

\footnotetext{
${ }^{12}$ Orozco Díaz, Emilio. «Tres obras de Pedro de Mena desconocidas». Goya, n. 30 (1959), p. 347. No se conservan versiones del Crucificado entre los dibujos atribuidos a Cano.

13 Orozco Díaz, E. «Un Ecce-Homo desconocido de Pedro de Mena y la interpretación de este tema en la escultura granadina». Goya, n. ${ }^{\circ} 71$ (1966), pp. 292-299. Cf. también López Muñoz, Juan Jesús. «El Ecce Homo en la escultura granadina. Imagen de devoción, imagen de procesión». Actas del III Congreso Nacional de Cofradías de Semana Santa. Córdoba, 1996. Córdoba, Cajasur, 1997, pp. 146-147.

${ }^{14}$ Sánchez-Mesa Martín, Domingo. «Algunas noticias sobre la obra de Pedro de Mena». Archivo Español de Arte, t. XL, n. ${ }^{\circ} 159$ (1967), p. 250 y ss. Orozco Díaz, Emilio. «Unas obras de Risueño y de Mora desconocidas». Archivo Español de Arte, t. XLIV, n. ${ }^{\circ} 175$ (1971), p. 250.
} 
Es evidente la lejanía que demuestra esta pieza de su directo magisterio, quizás realizada por algún seguidor en Granada. Pero sirve, por el contraste, para subrayar las caracterizaciones que ya hemos notado con respecto a la interpretación del desnudo en las imágenes cristíferas de Mena.

Este peregrinar por el análisis de modelos y antecedentes no sirve sino para estrechar lazos estilísticos y confirmar la calidad del Crucificado perdido en Málaga, sin duda una de las más importantes realizaciones de nuestro artista.

A éste se ha relacionado recientemente el Cristo del Perdón de la Catedral de Málaga, que Romero Torres sitúa en fecha anterior a $1680^{15}$. Se asemeja mucho al de Santo Domingo en su esquema compositivo muy vertical, el tórax hinchado, brazos cortos en relación con el cuerpo y contactos en su rostro con los de los Ecce-Homos de Mena o incluso con la Magdalena penitente del Prado. Pero «está muy retocado en la talla de su anatomía y, sobre todo, en su policromía, quedando al final una obra pobre y muy de taller» ${ }^{16}$. En efecto, un detenido examen revela carencias en la ejecución que impiden una atribución incontestable. Sin embargo, se observan con claridad soluciones que estudian los modelos de Mena. Es de destacar el paño de pureza, reducido y ceñido al cuerpo, que no es el del Cristo de Santo Domingo sino que elabora un esquema triangular cercano al desarrollado en otras obras, como en el Crucificado de la Magdalena penitente o el Ecce-Homo de la iglesia de Santa María de la Alhambra. Todo lo anterior nos da pie a estudiar los Crucificados de pequeño formato, apenas estudiados ni reproducidos, cuando no obviados.

\section{Los Crucificados de pequeño formato}

Más fortuna han corrido los Crucificados de pequeño formato, que nos llegan en primorosos ejemplares en manos de santos y santas. De esta clase, daríamos el primer puesto en orden cronológico al que sostiene entre sus brazos el San Francisco del convento del Ángel Custodio de Granada. María Elena Gómez-Moreno lo fecha en $1675{ }^{17}$ pero parece conveniente retrasar esta cronología, como propone el profesor Sánchez-Mesa ${ }^{18}$, al periodo previo al traslado de nuestro artista a Málaga en 1658 o en sus primeros años en aquella ciudad. Se enmarcarían este San Francisco y la Santa Clara compañera en los trabajos de Pedro de Mena para este cenobio de clarisas, entre ellos los santos franciscanos del Museo de Bellas Artes granadino, en colaboración con Cano, entre 1653-1657 aproximadamente. Otro hito cronológico lo constituye el final de las obras de la iglesia en 1661, según el relato del cronista Fray Tomás de Montalvo ${ }^{19}$.

Es una muestra más del gusto por la mística de Mena en la figura de este San Francisco que abraza amorosamente el Crucifijo, con un arrobo un tanto falto de expresión, que parece meditar los versos de Lope, como nos recuerda Sánchez Cantón:

\footnotetext{
15 Romero Torres, J. L., op. cit., p. 17.

16 Sánchez-Mesa Martín, D. «Cristo del Desamparo». En Pedro de Mena. III Centenario de su muerte. 1688-1988, p. 120.

17 Gómez-Moreno, María Elena. «Pedro de Mena y los temas iconográficos». En Pedro de Mena. III Centenario de su muerte. $1688-1988$, p. 87.

18 Sánchez-Mesa Martín, D. «San Francisco de Asís». En Pedro de Mena. III Centenario de su muerte. 1688-1988, p. 162.

${ }_{19}$ Montalvo, Fr. Tomás de. Vida prodigiosa de la extática Virgen y Venerable Madre sor Beatriz María de Jesús, abadesa que fue del convento del Ángel Custodio de Granada, de Religiosas Franciscas Descalzas de la más estrecha Observancia de la Primera Regla de Santa Clara. Chrónica del mismo convento y memoria de otras religiosas insignes en virtud. Granada, Imprenta. de Francisco Domínguez, 1719, p. 425. Al respecto vid. López Muñoz, J. J. et alii, op. cit., p. 145 y ss.
} 


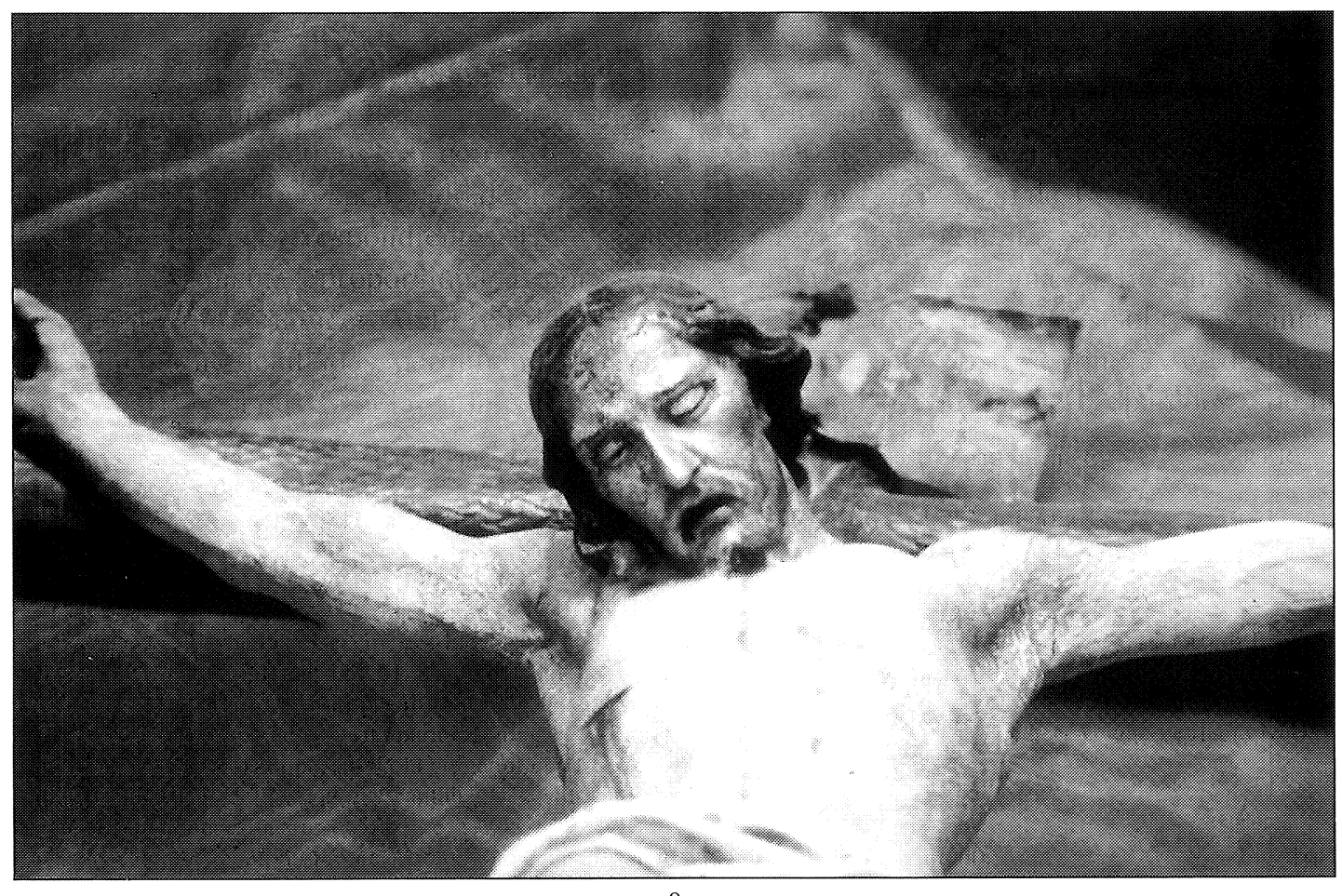

10

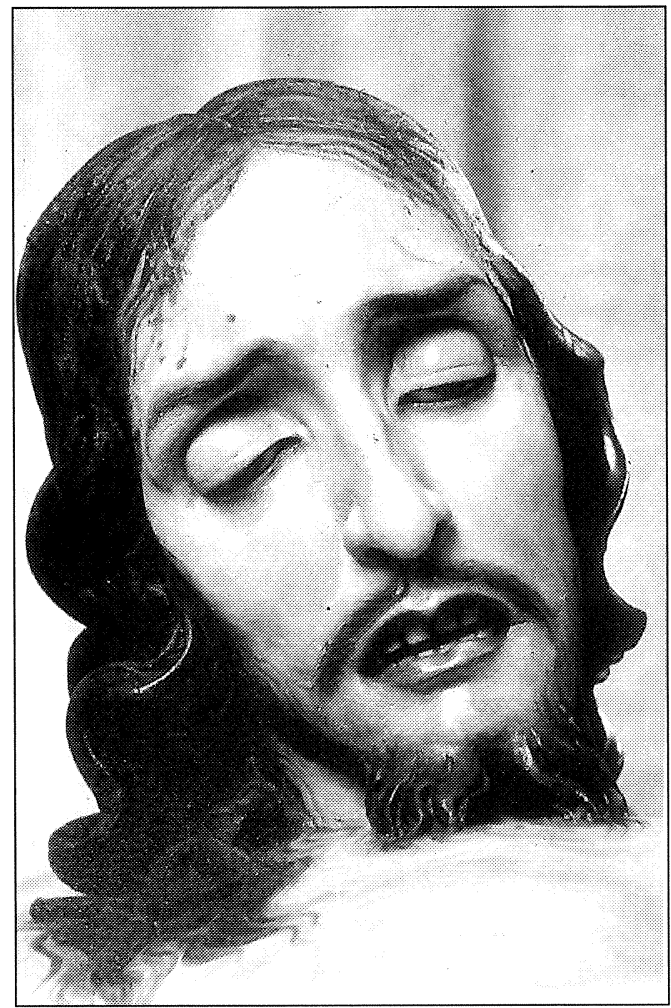

9

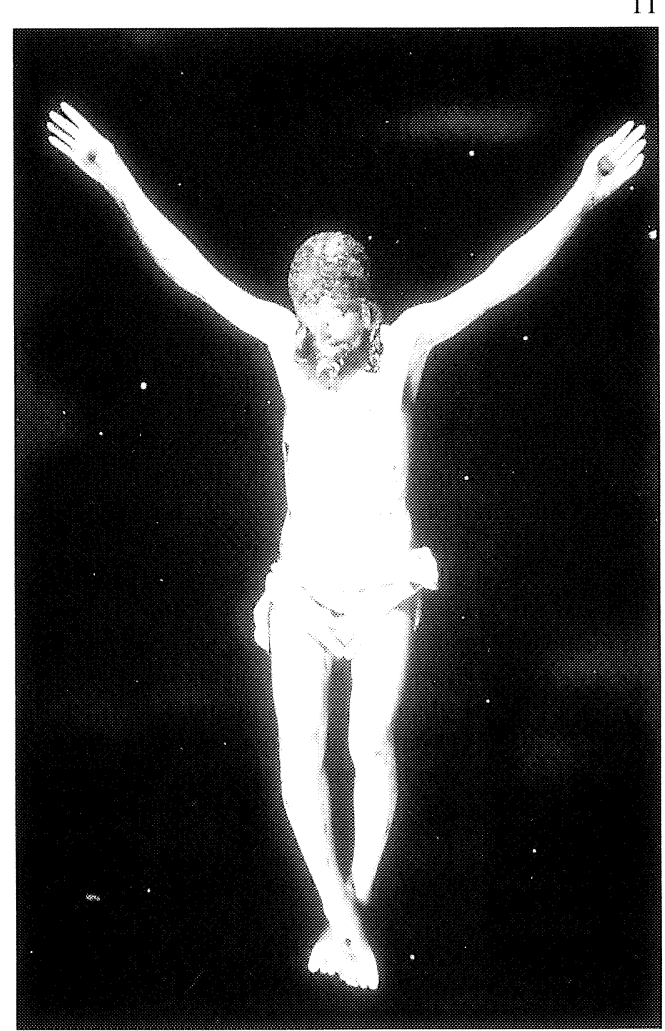

Fig. 9. Detalle del Crucificado de la imagen de San Francisco de Asís. I.P.H.-M.E.C. Fototeca de Obras Restauradas. Fig. 10. J. de Mora: Cristo de la Misericordia, detalle (h. 1673-74). Granada, iglesia parroquial de San José.

Fig. 11. Pedro de Mena: Cricificado de la imagen de la Magdalena Penitente (1664). Madrid, Museo del Prado. I.P.H.M.E.C. Fototeca de Obras Restauradas. 


\begin{abstract}
«Entre esas cinco llagas,
(oh, Cristo soberano!

y al son de sus corrientes,

comenzará mi llanto» ${ }^{20}$.
\end{abstract}

Es un fecundo encuentro el de la mística y la imaginería por su comunidad de intereses. Así, acierta Orozco al afirmar que «la intención del místico es también, como la del imaginero, mover a devoción, y así tiene que recurrir como éste a la acentuación de lo expresivo y de lo impresionante, sobre todo cuando trata del tema central de la meditación que es también el nervio de nuestra imaginería: los pasajes de la Pasión de Cristo» ${ }^{21}$. Los imagineros acercan al plano humano la trascendente búsqueda de Dios «al que (...) necesitan atraer y estrechar contra sí en la humanidad dolorida y sangrante de un Crucifijo» ${ }^{22}$.

Se trata de una pequeña escultura, de algo más de 20 centímetros de longitud (fig. 8), en la que recrea el tema con la misma calidad que en el probablemente posterior malagueño. El cuerpo se presenta perfectamente anatomizado y en cuanto a su disposición, la frontalidad marca de nuevo la serenidad de la figura, profundamente desplomada. Solamente marca un punto de tensión en el cruce de los pies, que realiza una diagonal de la que resultan, por una parte, una apertura de perfiles en la base de la imagen y, por otra, un ligero acortamiento de las piernas, que son las desproporcionadas en este caso. Al igual que en el malagueño, Cristo se desploma gravemente, como demuestra el acusado ángulo de inflexión de las rodillas, aunque no se acuse tanto el tirón de los brazos como en aquél. La cabeza de nuevo se hunde en el pecho, girada levemente hacia la derecha.

El modelo inspirador, también en este pequeño formato, sigue siendo Cano. Si la cronología que se propone es acertada, probablemente no conocía aún Mena el Crucificado de Cano en Montserrat de Madrid, lo que revaloriza la importancia ya mencionada de los modelos pictóricos del racionero, amén de la relación personal de ambos artistas durante las obras del convento del Ángel. Por otro lado, resulta una imagen muy bien elaborada, teniendo en cuenta su formato y que probablemente desde un principio el San Francisco estaría destinado a un lugar en alto. Su anatomía se explicita en un modelado aún más ligero que en el de Málaga pero perfecto para este tamaño. El paño de pureza es diferente, anunciando ya la composición triangular que repetirá Mena en varias ocasiones, realizado aquí en pliegues redondeados, sin duda necesarios para que se distingan en las reducidas dimensiones de la figura. Se observan en el tono general del pequeño Crucifijo soluciones plásticas de gran ligereza y maestría, correlato escultórico de un boceto rápido, resuelto a grandes trazos. En todo ello da buena muestra Mena de su virtuosismo técnico.

Por último, de lo más interesante resulta el estudio de la cabeza (fig. 9). Como en el modelo canesco, se hunde profundamente en el pecho, con el pelo apelmazado, pero sobre todo dibuja un rostro que es premonición de José de Mora (fig. 10), a través de la afilada nariz, los salientes pómulos, las sinuosas cejas y la fría laxitud de la boca entreabierta, dibujado todo ligera pero perfectamente. Quizás sea en estas soluciones donde la pequeña imagen se aparte más de lo que podríamos considerar el prototipo de Mena, a la luz del perdido Crucificado de Santo Domingo de Málaga. Cabe la interpretación de la colaboración de discípulos, pero también el ensayo de nuevas soluciones expresivas que quizás plasmara en gran formato, pero que,

\footnotetext{
${ }^{20}$ Citado por Sánchez Cantón, Francisco Javier. San Francisco de Asís en la escultura española. Madrid, Academia de Bellas Artes de San Fernando, 1926, p. 44.

${ }^{21}$ Orozco Díaz, E. «Mística y plástica (comentarios a un dibujo de San Juan de la Cruz)». Boletín de la Universidad de Granada, núms. 55-56 (1939), p. 274.

${ }_{22}$ Gallego Burín, Antonio. «Pedro de Mena y el misticismo español». Boletín de la Universidad de Granada, n1 7 (1930), p. 11
} 


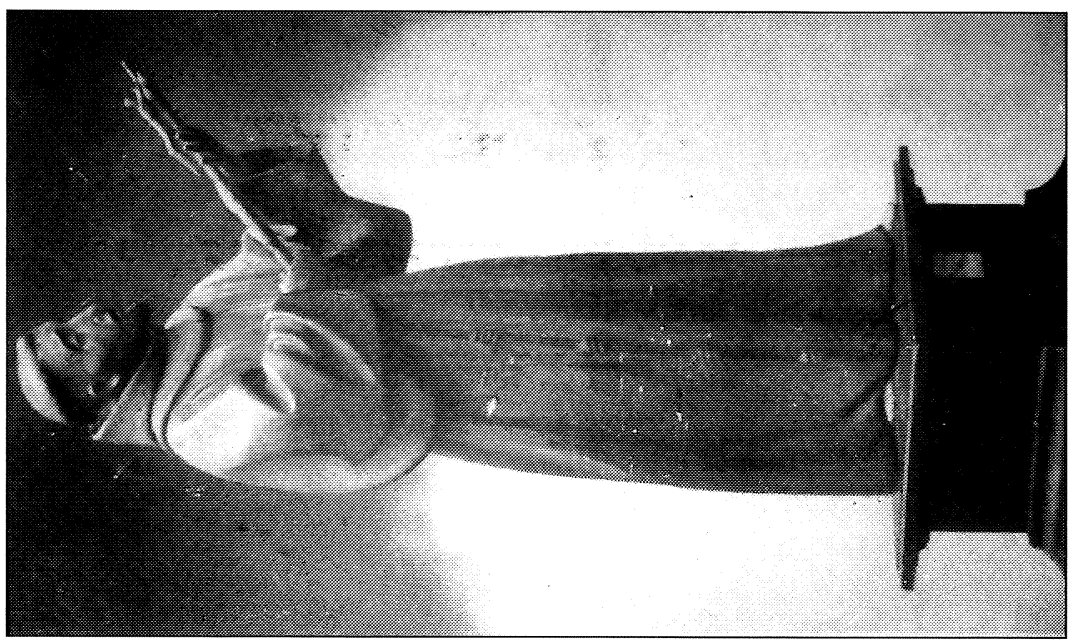

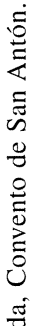
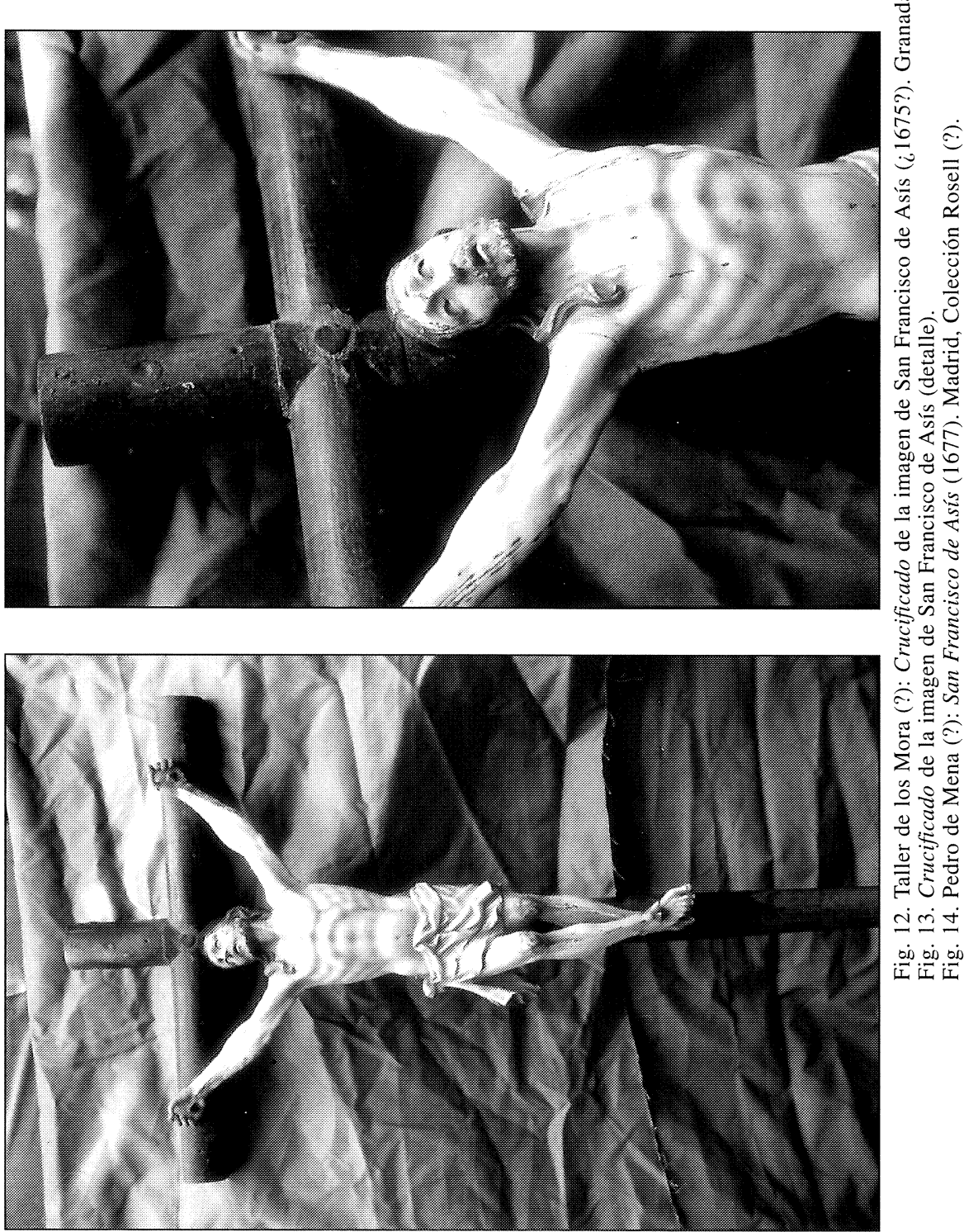

З

U

范

$\sum \frac{\pi}{0}$

용

응 용

氜

¿ $\dot{2} \dot{ \pm}$

os os oj

江江江 
por desgracia, no hemos llegado a conocer. En definitiva, es una imagen de gran calidad, en la que Mena recrea el modelo de Cano, imponiendo su calidad técnica, su valoración plástica y su hondo sentimiento, avanzando futuros logros y nuevas propuestas plásticas y expresivas que ensanchan el campo de la tipología de sus Crucificados. Creo que en su estela podría ubicarse el Crucificado que porta el San Francisco de Asís de Fernando Ortiz de la Catedral de Málaga, que publica el profesor Sánchez López ${ }^{23}$, con mayor robustez anatómica.

Cercano en el tiempo está el Crucificado de la Magdalena penitente, imagen recientemente restaurada, que es propiedad del Museo del Prado. Esta imagen constituye «la más perfecta expresión del sentimiento místico en la estatuaria de Mena», según María Elena Gómez-Moreno ${ }^{24}$, y fue realizada en 1664 para la casa profesa de los jesuitas en Madrid. Ello introduce un punto de reflexión para estudiar la imagen pues, como nos recuerda Weisbach, «hay que partir siempre de este sistema - el ignaciano - si queremos comprender el sentido religioso y espiritual de la Contrarreforma (...). Su práctica desarrollaba el poder de transformar las representaciones religiosas en una intuición sensible muy concreta y de identificar esta imagen elaborada por la fantasía con un sentimiento adecuado a su significación» ${ }^{25}$.

Sobre la autoría y la cronología no queda, pues, ninguna duda ya que la propia escultura está firmada. Esto acrecienta el interés del análisis de su Crucifijo (fig. 11). De 22 centímetros aproximadamente de longitud, se advierten claramente notas características en Mena como la frontalidad y verticalidad de la imagen, lo somero del modelado, lo hundido de la cabeza o el esquema triangular del perizoma. Salvo en esta última prenda, se encuentra este Crucificado más cercano al desaparecido de Málaga que el del San Francisco del Ángel Custodio de Granada, lo que corroboraría para el malagueño una cronología inmediatamente posterior al viaje de Mena a Madrid de 1663-1664.

Conviene que no pasen inadvertidos algunos detalles de esta imagen. El paño presenta el esquema triangular mencionado, muy ceñido y con pliegues a ambos lados de la cintura, separándose bastante del de Málaga pero marcando, sin embargo, el tipo más propio de Mena. El modelado, por otra parte, aparece más someramente tratado que en el caso anterior, restando empeño, que no belleza y calidad, al pequeño Crucifijo. En cuanto al rostro, finalmente, se logra advertir la barba partida en dos picos que tanto repite en sus Ecce-Homos. Digamos que, en este caso, ensaya un tipo más conceptual y esquemático, donde el recuerdo de Cano late en la composición de la pequeña figura, especificada en detalles propios de gubia tan perita como la de Mena.

María Elena Gómez-Moreno señala la existencia de una Magdalena en pequeño formato (65 centímetros), a la que ya a comienzos de nuestro siglo faltaba el Crucifijo, firmada por Mena en 1677, que provenía de un convento de Madrigal y que aún hoy está en paradero desconocido ${ }^{26}$. En ella se prolongaría no sólo el éxito de la iconografía de esta santa, sino también la serie de Crucificados en pequeño formato.

La siguiente imagen de la serie es el Crucificado del San Francisco del granadino convento de San Antón. Don Manuel Gómez-Moreno en su Guía de Granada afirma ser de Pedro de Mena y la fecha en 1675. Esta autoridad ha bastado para ser aceptada por otros investigadores (Orueta, Gallego Burín, María Elena Gómez-Moreno) ${ }^{27}$. Gómez-Moreno, como es frecuente,

\footnotetext{
${ }^{23}$ Sánchez López, Juan Antonio. El alma de la madera. Cinco siglos de iconografía y escultura procesional en Málaga. Málaga, 1996, p. 209.

${ }^{24}$ Gómez-Moreno, M. ${ }^{a}$ E. «Escultura del siglo XVII». Ars Hispaniae. Madrid, 1963, t. XVI, p. 250.

25 Weisbach, Werner. El Barroco, arte de la Contrarreforma. Madrid, 1942, pp. 65-66.

${ }^{26}$ Gómez-Moreno, M. ${ }^{a}$ E. «Escultura del siglo xviI», p. 253; y «Pedro de Mena y los temas iconográficos». En Pedro de Mena. III Centenario de su muerte. 1688-1988, p. 89.

${ }^{27}$ Gómez-Moreno, Manuel. Guía de Granada. Granada, Imprenta de Indalecio Ventura, 1892 (ediciones facsímiles en Granada, Universidad-Fundación Rodríguez-Acosta, 1982 y 1994), p. 398; Orueta y Duarte, R. de, op. cit., pp. 222-223; Gallego Burín, A. Granada. Guía artística e histórica de la ciudad. Granada, Comares, 1989, p. 199; Gómez-Moreno, M. ${ }^{2}$ E. «Escultura del siglo XvII», p. 250.
} 
no cita la fuente de tan precisa afirmación. A pesar de lo cercano que está del San Francisco del convento del Ángel en la concepción de la figura, algo en ella y, sobre todo, en el rostro nos lo acerca a los Mora, como ya ha advertido el profesor Sánchez-Mesa ${ }^{28}$.

Por lo que respecta al Crucificado que ase con la mano derecha (figs. 12 y 13), éste se muestra en todo distinto a los anteriores. Algo mayor que aquéllos (unos 28 centímetros aproximadamente), Cristo se presenta con tres clavos y expirante, con el rostro vuelto hacia arriba. Su modelado, de gran detallismo, es duro y anguloso, casi como si de una escultura en marfil se tratase, material que, por cierto, también trabajó Mena, aunque poco, al decir de Palomino ${ }^{29}$. Aunque frontal, el esquema es más dinámico que en los otros ejemplos, como demuestra el arqueo de la pierna derecha y el alzamiento y giro a la derecha del rostro del agonizante. El rostro tampoco recuerda a lo conocido de Mena, mucho más ancho y menos alargado, con la barba redondeada y la complexión más robusta que lo habitual en nuestro artista. Tampoco el perizoma revela relación directa con él: es más largo, casi hasta la rodilla, de voluminosos pliegues y anudado con un paño volado a la derecha. A la vista de todo ello, se hace difícil pensar en la intervención de Mena en la ejecución del pequeño Crucificado, ni aún intentando romper con el tipo más común en él, por lo que parece prudente pensar en otra mano ${ }^{30}$.

Existe otro San Francisco que empuña el Crucifijo con ambas manos y que perteneció a la colección Rosell, pero que hoy tampoco se encuentra. Según Gallego Burín, estaba firmado en Málaga en 1677 y era imagen de gran finura y distinta disposición a los anteriores ${ }^{31}$. Lo conocemos sólo a través de una antigua reproducción fotográfica que nada revela del Crucificado (fig. 14).

Por último, en el Museo Marès de Barcelona se conserva una Magdalena penitente, catalogada como del taller de Pedro de Mena, siguiendo de cerca el modelo de nuestro artista ${ }^{32}$. Parece encontrarse en regular estado de conservación, con deterioros en pies y manos, abiertas las juntas en los hombros y bastante perdidos tanto la policromía como el modelado. Sí sigue el esquema de serena verticalidad que frecuenta Mena pero con un canon alargado inédito en él. El perizoma, por su parte, tampoco cultiva su tipo común.

\section{Conclusiones}

A modo de conclusión, cabe señalar que en una línea artística tan inequívocamente definida por lo religioso, como la de Pedro de Mena, es difícil creer que tratara el tema del Crucificado en tan contadas ocasiones. Sin duda, no se han conservado o encontrado pero no debió omitir tal tema, como corroboran las referencias que se han citado. Por otro lado, del elenco presentado, poco se puede asegurar de su mano, a no ser el perdido de Santo Domingo de Málaga y los del San Francisco del Ángel Custodio de Granada y de la Magdalena penitente del Prado. Resultaría, asimismo, muy revelador el del San Francisco de la colección Rosell, escultura firmada, al parecer, en 1677.

\footnotetext{
${ }^{28}$ Sánchez-Mesa Martín, D. «San Francisco de Asís». En Pedro de Mena. III Centenario..., p. 162.

${ }^{29}$ Palomino de Castro y Velasco, A. A., op. cit., p. 1067.

${ }^{30}$ No resulta fácil adjudicarlo a los cultivadores granadinos de la escultura eboraria, cuyo estudio no ofrece aún suficiente precisión de autoría (cf . Estella Marcos, Margarita. La escultura barroca de marfil en España. Madrid, CSIC, 1984; Capel Margarito, Manuel. «La colección de marfiles de la Orden Hospitalaria de Granada». Cuadernos de Arte de la Universidad de Granada, XVIII (1987), pp. 63-85). Cabe clasificar provisionalmente este Crucificado en el taller de los Mora, a tenor del resto del conjunto escultórico.

${ }^{31}$ Gallego Burín, A. «Pedro de Mena y el misticismo español», p. 26 y fig. 6.

${ }^{32}$ Sánchez-Mesa Martín, Domingo. «Pedro de Mena o taller. Magdalena penitent». En Fons del Museu Frederic Marès/ 3. Catàleg d'escultura i pintura dels segles XVI, XVII $i$ XVIII. Barcelona, Ayuntamiento, 1996, p. 327.
} 
En este sentido, el estudio de detalle de los Crucificados de pequeño formato en Pedro de Mena, hasta ahora sin abordar, revela especial interés tanto por el hecho de no conservarse ninguna versión del tema a tamaño mayor, como por la libertad compositiva y pericia técnica que acreditan. En efecto, a falta de otras versiones, comprobamos los ensayos de Mena en estas espléndidas realizaciones donde las soluciones plásticas fluyen libremente a la hora de definir en breves trazos maestros un modelo de Crucificado que sorprende y renueva lo conocido en Mena en gran formato, para constituir ese eslabón perdido en la secuencia del Crucificado barroco granadino. Admira, desde luego, el esfuerzo conceptualizador, la capacidad técnica y la renovación formal que estas piezas, que suelen pasar inadvertidas, documentan en la producción del maestro granadino.

Por último, hay que resaltar que el sello canesco es notable en modelos y conceptos, debiendo ponderar la real importancia de los modelos pictóricos — más, quizás, que los escultóricos-, a pesar de lo cual Mena solventa estas creaciones, como en otras ocasiones, con fuerte personalidad y gran virtuosismo técnico. Expresa, en definitiva, un sentimiento religioso colectivo, de índole ascético-mística, pero en individual plasmación. 